\title{
1 Carbon nanofiber-based counter electrodes for low cost dye-sensitized
}

\section{solar cells}

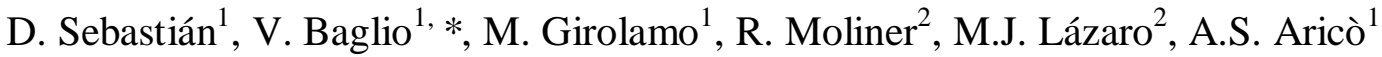 \\ ${ }^{1}$ Istituto di Tecnologie Avanzate per lâEnergia ñNicola Giordanoò (CNR), via Salita S. Lucia \\ sopra Contesse, 5 - 98126 Messina, Italy \\ ${ }^{2}$ Instituto de Carboquímica (CSIC), C/Miguel Luesma Castán, 4 ї 50018 Zaragoza, Spain \\ *Corresponding author: baglio@itae.cnr.it
}

\section{Abstract}

Carbon materials represent an attractive alternative to platinum in dye-sensitized solar cells (DSSC) counter electrodes to contribute to an efficient conversion of solar energy into electricity. The use of highly graphitic carbon nanofibers (CNFs) is investigated by analyzing the effect of the filament diameter, surface area and graphitization degree on the DSSC cathode performance. To this purpose, transmission electron microscopy (TEM), X-ray diffraction (XRD), Raman spectroscopy and physisorption analysis are used to characterize the main properties of the CNFs. The behavior of CNFs as counter electrodes in DSSC is investigated by polarization experiments and electrochemical impedance spectroscopy. Among the different materials, the CNF characterized by the highest surface area $\left(183 \mathrm{~m}^{2} \mathrm{~g}^{-1}\right)$, thinnest filament size $(24 \mathrm{~nm})$ and highest density of surface defects shows the best performance in terms of efficiency, open circuit potential and short circuit current density. Further investigation of the electrode thickness together with series and charge transfer resistance cross-analysis evidences the key role played by the surface area and surface graphitization to obtain a suitable performance. Compared to literature, so-obtained CNFs represent an interesting alternative to manufacture low cost DSSC cathodes.

Keywords: Dye-sensitized solar cells; Carbon nanofibers; Counter electrode. 


\section{Introduction}

Dye-sensitized solar cells (DSSCs) are well known as potentially low-cost photovoltaic devices [1] and have attracted great attention the last years for their capability to provide low cost power [2-6]. DSSC components include a photoanode based on a metal oxide semiconductor, organic sensitized dyes, an iodide solution as electrolyte and a counter electrode (CE) based on a noble metal thin film. The CE tasks are the collection of electrons from the external circuit and the reduction of the redox species used as a mediator in regenerating the sensitizer after electron injection into the photo-anode. The benchmark catalyst in the CE in most of the recent publications in this field is platinum [7-12] because of the high catalytic activity and high corrosion stability against iodine in the electrolyte. Currently, efforts are directed to develop low cost materials with good chemical stability and high catalytic activity for the reduction of the triiodide ion to replace Pt.

Carbonaceous materials are quite attractive to replace platinum due to their high electronic conductivity, corrosion resistance towards $\mathrm{I}_{2}$, high reactivity for triiodide reduction and low cost [13-22]. The lower intrinsic catalytic activity of carbon compared to platinum is compensated by the considerably larger active surface area of the electrode structure that characterizes porous carbon materials, providing a large number of reduction sites and hence low charge transfer resistance. A high graphitic character is nevertheless necessary to provide sufficient electrical conductivity to the thin-film carbon electrode, so graphitic materials such as graphite, graphene, carbon nanotubes and carbon nanofibers have been explored [23]. In this regard, it has been very recently reported that carbon nanofibers (CNFs) and carbon blacks generally exhibit superior efficiencies and fill factors to graphite and graphene because their surface structure possesses a larger amount of catalytic sites providing faster reaction kinetics [23]. To the best of our knowledge, the few works report the electrochemical behavior of CNFs as CE in DSSC based on fibers with large diameters $(200-250 \mathrm{~nm})$ and a low graphitization degree. These are generally 
1 synthesized by electrospinning and show promising performances [24,25] also in combination with metals such as Ni [26], Ni-Cu [27], Pd-Co [28] or Pt [29].

In this work, herringbone CNFs characterized by small diameters $(10-80 \mathrm{~nm})$ and a high graphitization degree are studied as counter electrode for DSSC. The high graphitic character of CNF will provide good electron conduction, enhancing the electrode performance. On the other hand, the herringbone structure will provide a high surface density of carbon edge active sites, whereas thin nanofilaments will provide high surface area. Moreover, the main characteristics of CNFs are susceptible to be tuned by the adequate choice of synthesis conditions. Here we have varied the synthesis temperature for the catalytic decomposition of methane on nickel nanoparticles and studied both physico-chemical and electro-chemical properties. CNFs are also characterized by a low cost when compared to similar carbonaceous structures like carbon nanotubes. The current market of this kind of materials points to prices in the order of $0.30 \$ \mathrm{~g}^{-1}$ for CNFs, $0.80 \$ \mathrm{~g}^{-1}$ for multiwall nanotubes (MWNT) and $65 \$ \mathrm{~g}^{-1}$ for single wall nanotubes (SWNT) [30,31]. Compared to the price of platinum [32], i.e. the benchmark CE material, which is found around $50 \$ \mathrm{~g}^{-1}$, the choice of CNFs appears as an economically interesting alternative for the CE of DSSCs.

As in a previous work from our group [33], the photo-anode was prepared by using a very simple procedure aimed to produce low cost components. In order to avoid side effects related to the use of an efficient but complex photoanode layer, we have just focused our efforts on a simple photoanode configuration to get information specifically related to the counter-electrode behaviour. The photoanode consisted of a deposition of the $\mathrm{TiO}_{2}$ layer on the F-doped $\mathrm{SnO}_{2}$ (FTO) glass substrates by a spray technique and successive heat treatment at $450^{\circ} \mathrm{C}$, without any further process. Usually, an optimized electrode is formed by using various procedures and treatments to give high electrochemical performance [34-38]. FTO, after cleaning, is usually immersed in $40 \mathrm{mmol} \mathrm{L}^{-1}$ $\mathrm{TiCl}_{4}$ aqueous solution at $70^{\circ} \mathrm{C}$ for 30 minutes and successively washed with water and ethanol. The glass is then treated at $450^{\circ} \mathrm{C}$ for 30 minutes [34]. Afterwards, a $\mathrm{TiO}_{2}$ paste is coated on this 
1 modified FTO glass by doctor blade or screen printing techniques to obtain a $\mathrm{TiO}_{2}$ film of 8-15 $\mu \mathrm{m}$.

2 This film is dried at $125^{\circ} \mathrm{C}$. Successively, a $\mathrm{TiO}_{2}$ light-scattering layer of $4-5 \mu \mathrm{m}$ is added by using

3 titania particles of about $200 \mathrm{~nm}$ in size. The double-layer $\mathrm{TiO}_{2}$ film is gradually heated under an air

4 flow up to $500^{\circ} \mathrm{C}$ [34]. According to this procedure, the preparation of an optimized electrode is

5 quite expensive and time consuming for a large scale production. In this work, a simple procedure is

6 adopted for the photoanode manufacturing but providing lower overall performance. However, this

7 procedure is highly reproducible and appears as the most useful to compare the counter electrode 8 effects. 


\section{Experimental}

Carbon nanofibers (CNFs) were in-house synthesized by the catalytic decomposition of methane as reported in previous works [39]. Briefly, a nickel based catalyst, $\mathrm{Ni}_{39} \mathrm{Cu}_{3}\left(\mathrm{Al}_{2} \mathrm{O}_{3}\right)_{4}$, was prepared by co-precipitation of the corresponding nitrates in appropriate amounts, calcination in air and subsequent reduction in hydrogen. The CNFs were grown flowing pure methane to this Nibased catalyst at four different temperatures from $550{ }^{\circ} \mathrm{C}$ to $750{ }^{\circ} \mathrm{C}$, in order to obtain carbonaceous materials with varied properties according to previous works [40]. The growth time was adjusted in every experiment so as to obtain a carbon content of $95 \mathrm{wt} \%$, corresponding to an approximate aspect ratio of 50 (length/diameter ratio). The reaction progress was monitored by continuously analyzing the outlet gas concentration of methane and hydrogen by gas chromatography (micro-GC Varian CP4900).

X-ray diffraction analysis (XRD) of the carbon powders was carried out with a Bruker AXS D8 Advance diffractometer, with a of đơnconfiguration and using $\mathrm{Cu}-\mathrm{KU}$ source. Raman spectra were recorded on powder samples with a Horiba Jovin-Yvon HRLAB HR 800 UV apparatus using an excitation laser with a wavelength of $532 \mathrm{~nm}$. High-resolution transmission electron microscopy (HRTEM) images were obtained using a JEOL-2000 FXII microscope at $200 \mathrm{kV}$ and a spatial resolution of $0.28 \mathrm{~nm}$. The samples were finely grinded and ultrasonically dispersed in ethanol. A drop of the resultant dispersion was deposited and dried onto a standard copper grid coated with Lacey carbon.

The porous structure of carbon nanofibers was evaluated by means of nitrogen adsorptiondesorption isotherms at $-196^{\circ} \mathrm{C}$, using a Micromeritics ASAP 2020. Total surface area and pore volume were determined using the Brunauer-Emmet-Teller (BET) equation and the single point method, respectively. The carbon nanofibers real density was determined by helium pycnometry at $30^{\circ} \mathrm{C}$ using a Micromeritics AccuPyc II 1340 pycnometer. 
To study the electrical conductivity, the samples were placed in a thick-walled PVC tube with an inner diameter of $8 \mathrm{~mm}$ and closed with two metal plungers. Stable loads were applied on the samples, leading to pressure values from $0.5 \mathrm{MPa}$ to $30 \mathrm{MPa}$, monitored by a calibrated pressure sensor. The height of the sample was measured using a digital micrometer (Mitutoyo) with an accuracy of $\pm 0.02 \mathrm{~mm}$. The apparent density of the sample was easily calculated from its weight, determined with an accuracy of $\pm 0.1 \mathrm{mg}$, and the volume of the cylinder, which decreases with pressure. Then the $d c$ electrical resistance of the pressed powder was determined applying known values of potential with a power supply (Array 3645A), scanning current values up to $20 \mathrm{~mA}$, and the voltage drop in the resistors (sample and calibrated) were registered with a $6 \frac{1}{2}$ digits Array M3500A multimeter. The electrical conductivity was then calculated from resistance value, obtained in turn from the adjustment of voltage and current slope, and geometric parameters. The system contribution to the total resistance (about 100-150 ma) was removed from the experimental resistance, determining it before each experiment with the empty system.

Working electrodes and counter electrodes were prepared on F-doped $\mathrm{SnO}_{2}$ glass (sheet resistance: $15 \mathrm{q} / \mathrm{l}$ ) substrates (FTO). The $\mathrm{TiO}_{2}$ paste for the photo-anode was prepared from commercial powder (Degussa P90) and deposited by a spray technique onto the substrate. Afterwards, electrodes were sintered at $450^{\circ} \mathrm{C}$ for 30 minutes; the sintering process allows the titanium dioxide nanocrystals to melt partially together, in order to ensure electrical contact and mechanical adhesion on the glass. Dye sensitization was carried out by immersing the sintered electrodes in $0.5 \mathrm{mM} \mathrm{N719} \mathrm{solution} \mathrm{(Solaronix)} \mathrm{in} \mathrm{ethanol} \mathrm{for} \mathrm{about} 16$ hours. Electrolyte consisted of 0.4 M LiI, 0.04 M I $2,0.3 \mathrm{M}$ 4-tertbutylpyridine (TBP) and 0.4 M tetrabutylammonium iodide (TBAI) in acetonitrile. Carbon nanofibers were mixed with a $15 \%$ w/w of $\mathrm{TiO}_{2}$ (Degussa P90) as binder. The powders were dispersed in ethanol. Counter electrodes were prepared by spraying the slurry of carbon nanofibers onto FTO/glass substrates, and then electrodes were sintered at $450^{\circ} \mathrm{C}$ for 10 minutes. 
A spacer thick $100 \mathrm{\varepsilon m}$ was used to allocate the electrolyte between the photo-anode and the

counter electrode. Generally, the spacing between these electrodes is about $30 \mathrm{\varepsilon m}$ in the state-of-art DSSCs to avoid ohmic constraints. Yet, being the aim of this work addressed to compare different materials in the same conditions, we have preferred to use a suitable amount of liquid electrolyte in between the two electrodes in order to avoid short circuit effects and improve reproducibility of the cells.

Current-voltage curves of the devices were recorded under simulated AM 1.5 solar illumination (Osram, $300 \mathrm{~W}$ ) at $25^{\circ} \mathrm{C}$. The incident light intensity was adjusted to $100 \mathrm{~mW} \mathrm{~cm}^{-2}$ by using a photometer (3M Photodine Inc.). The cells operating under simulated solar illumination were connected to an Autolab Potentiostat/Galvanostat (Metrohm) equipped with an FRA. The active area of the cells was $0.25 \mathrm{~cm}^{2}$. EIS measurements were carried out at room temperature in the frequency range $100 \mathrm{mHz}-1 \mathrm{MHz}$ at open circuit voltage (OCV); the amplitude of potential pulse was $0.01 \mathrm{~V}$.

A short time-study was carried out in a half-cell configuration to avoid side effects from photoanode or electrolyte. A saturated calomel electrode $\mathrm{Hg} / \mathrm{Hg}_{2} \mathrm{Cl}_{2}$ (sat.) was used as reference electrode and a high surface area platinum grid was used as counted electrode. The working electrodes were prepared under the same procedure followed for the DSSC cells, with an active area of $1 \mathrm{~cm}^{2}$. The electrolyte consisted on $0.4 \mathrm{M} \mathrm{LiI}, 0.04 \mathrm{M} \mathrm{I}_{2}, 0.3 \mathrm{M}$ 4-tertbutylpyridine (TBP) and 0.4 M tetrabutylammonium iodide (TBAI) in acetonitrile 


\section{Results and discussion}

The structure, graphicity and porosity of carbon nanofibers were investigated by XRD, Raman spectroscopy, TEM and physisorption analysis. Fig. 1 shows the XRD patterns of the pristine CNFs. They are characterized by a peak at $2 \theta=26.1-26.4^{\circ}$ representing the $(002)$ reflection due to the ordered graphitic structure. It is remarkable that increasing CNF synthesis temperature leads to narrower (002) peaks, centered at slightly higher diffraction angle, which means an enhancement of CNF graphicity with synthesis temperature. This is also evidenced by the increase of the carbon crystal domain size in the $c$-axis as shown in Table 1, varying from $6.0 \mathrm{~nm}$ to $9.6 \mathrm{~nm}$. Notice also that nickel related peaks $\left(2 \theta\right.$ of $44^{\circ}, 52^{\circ}$ and $\left.54^{\circ}\right)$ appear as low intensity contribution in Fig. 1, indicating a low content of metallic particles within the nanofibrous structure. Raman analysis was carried out to CNFs and the relative intensity between disordered related peak $\left(\mathrm{I}_{\mathrm{D}}\right)$ and graphitic related peak $\left(\mathrm{I}_{\mathrm{G}}\right)$ are summarized in Table 1. Generally, growing disorder of the CNFs is reflected in increased values of $I_{D}: I_{G}$ ratio, indicating an increase in the edge to basal planes ratio, a higher defect density, and/or a decrease in the crystallite size. Raman results indicate a higher graphitization degree as synthesis temperature rises, according to XRD results.

TEM images of the various CNFs are presented in Fig. 2. All CNFs present the typical 1D structure of filamentous carbon. The graphene layers orientation corresponds to a herringbone structure in which partitioned stacked nanocones constitute the nanofilaments. This structure is preferable to the nanotube structure (concentrically nested graphenes) since the density of surface edge carbon is considerably higher with respect to the density of basal planes, and thus improves the activity towards redox processes [23]. The filament average diameter varies with synthesis temperature as catalyst particles (Ni-based) grow as a result of sintering, resulting in CNFs of 24 $\mathrm{nm}$ at $550^{\circ} \mathrm{C}$ and $63 \mathrm{~nm}$ at $750^{\circ} \mathrm{C}$, as determined counting more than 100 filaments for every sample. Increasing filament size leads to the decrease of both surface area $\left(\mathrm{S}_{\mathrm{BET}}\right.$, Table 1$)$ and pore volume ( $\mathrm{v}_{\text {pore}}$, Table 1) and so increase of apparent density. In practice, high surface area means 
more active sites for the triiodide reduction in a DSSC, whereas high pore volume may favor the mass transport but hinder the electronic conductivity, as will be seen later. Nevertheless, as shown in Fig. 3, the adsorption isotherms correspond with porous carbons with a negligible microporosity, evidenced by the adsorption at high relative pressure, i.e. a meso-macro porosity which may facilitate the contact with the electrolyte in DSSCs.

Fig. 4 shows the variation of the bulk electrical conductivity of CNF powder with applied pressure. The curves follow the typical trend associated to deformation of particles (plastic or elastic), with a higher slope at low pressure than that at high pressure. In a porous graphitic-like carbon like CNF, the most important contribution to resistance is located at the interface between nanofibers and at the interface between the particles of different aggregates. In this regard, not only the graphicity index, but the spatial arrangement of the nanofilaments also plays a key role. As a result, it is observed an important increase of the electrical conductivity of CNFs with synthesis temperature. At low pressure, for example, the conductivity passes from about $60 \mathrm{~S} \mathrm{~m}^{-1}$ for the CNF grown at $550{ }^{\circ} \mathrm{C}$ to $400 \mathrm{~S} \mathrm{~m}^{-1}$ for the $\mathrm{CNF}$ grown at $750{ }^{\circ} \mathrm{C}$ (Fig. 4), highlighting the contribution of both graphicity and porosity.

Fig. 5 shows the photocurrent-voltage characteristics of DSSCs using the different CNFs as counter electrodes. Carbon nanofibers prepared at $550^{\circ} \mathrm{C}$ show the highest efficiency, together with a significantly higher open circuit voltage, $V_{o c}$, and short-circuit current density, $j_{s c}$, compared to the other CNFs synthesized at higher temperatures (see also Table 2). CNF550 shows the best porosity structure in terms of mesopore volume and surface area available for the reduction of $\mathrm{I}_{3}{ }^{-}$ions, which appears to be a critical factor in CNF-based counter electrodes since their intrinsic graphitic character provides sufficient electron conduction.

The conversion efficiency (d) is defined as follows:

$$
\eta(\%)=\frac{V_{O C} j_{S C} F F}{P_{S}}
$$


1 where $P_{s}$ stands for the power density of the incident illumination $\left(100 \mathrm{~mW} \mathrm{~cm}^{-2}\right)$, and the fill factor

2 is calculated as:

4 where $j_{m}$ and $V_{m}$ are the current density and the voltage for maximum power output, respectively. All calculated parameters are summarized in Table 2 for the CNF-based counter electrodes. The effect of CNF surface area and crystallinity on different parameters is reported in Fig. 6. Notice that the efficiency progressively increases with the BET surface area of CNFs (see Table 1), from 1.75 $\%$ for the sample CNF750 ( $\mathrm{S}_{\text {BET }}$ of $\left.92 \mathrm{~m}^{2} \mathrm{~g}^{-1}\right)$ up to $2.17 \%$ for the sample CNF550 ( $\mathrm{S}_{\text {BET }}$ of $183 \mathrm{~m}^{2}$ $\left.\mathrm{g}^{-1}\right)$. The contribution of crystallinity appears to be of less importance than that of porosity, since the CNFs characterized by the lowest surface area but the highest crystallinity (CNF750) shows the lowest efficiency (Fig. 6a). With regard to fill factor, there is no clear effect of CNF parameters (Fig. 6a). CNF550 presents the lowest FF but the highest efficiency. The efficiency trend with CNF features is further confirmed in Fig. $6 \mathrm{~b}$, where $j_{s c}$ and $V_{o c}$ are reported. The $j_{s c}$ is favored by a high surface area and low crystallinity of CNFs. On the other hand, the open circuit voltage is not particularly affected by CNF characteristics. This behavior highlights the important contribution of porosity in CNF-based counter electrode for DSSCs. The values of efficiency are yet lower than those reported in the literature for similar carbon-based materials; it is pointed out that this is mainly due to the use of a simple but reproducible photo-anode fabrication and a large thickness for the electrolyte spacer used in the present investigation.

The performances here reported are in line with a previous study from our group concerning other carbon materials and Pt-based counter electrodes [41]. In the present work a simple photoanode configuration has been used to avoid side effects and the attention was focused on the behavior related only to the counter-electrode. Possibly, using a more efficient but complex photoanode should lead to higher efficiency values. The advantage of using CNFs instead of carbon blacks is

$$
F F=\frac{V_{m} j_{m}}{V_{O C} j_{S C}}
$$


1 the presence of meso-pores that are accessible for the $\mathrm{I}_{3}{ }^{-}$reactant; whereas, carbon blacks show a

large occurrence of micro-pores that are not useful for the reaction. Furthermore, the high graphitic character of these materials in conjunction with a suitable surface area makes CNFs very promising as low cost counter electrodes for DSSCs. In fact, the high surface area of carbon-based materials compensates their lower catalytic activity compared to platinum. In terms of cost, the CE loading and the maximum performance must be considered. In the case of bare Pt [41], the loading is about

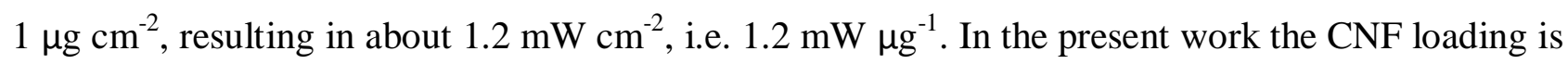

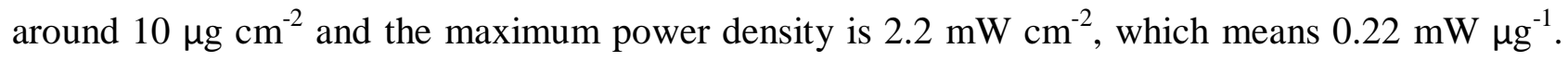
Taking into account that CNF price is two orders of magnitude lower than that of Pt [30-32], the CE based on CNFs is one order of magnitude cheaper (about $4 \$ \mathrm{~kW}^{-1}$ ) than a CE based on Pt (about 40 $\$ \mathrm{~kW}^{-1}$ ) under the same conditions.

Electrochemical Impedance Spectroscopy (EIS) has been widely used to investigate the interfacial charge transfer processes occurring in DSSCs [42]. The Nyquist plots reported in the literature for DSSCs consist of two [43] or three [42] semicircles. These are generally related, in order of decreasing frequency, to counter electrode/electrolyte interface, $\mathrm{TiO}_{2} /$ electrolyte interface and mass transport of $\mathrm{I}_{3}{ }^{-}$species in the electrolyte. Electrochemical impedance spectra for DSSCs using several CNF-based counter electrodes are showed in Fig 7. Our ac-impedance spectra essentially show two semicircles. In addition, the onset of a linear behaviour with a slope of about $45^{\circ}$ is observed for all cells at very low frequencies (Fig. 7). This is indicative of a Warburg-like diffusion component possibly related to the diffusion of ionic species at the $\mathrm{TiO}_{2}$ interface. The $a c$ response due to the mass transport of $\mathrm{I}_{3}{ }^{-}$species should occur at frequencies lower than those here investigated i.e. $0.1 \mathrm{~Hz}$ (a large scattering was recorded below this frequency).

Since the performance of the counter electrode may affect also the electrochemical behavior of the working electrode, we have considered in our analysis the total contribution to the charge transfer resistance $R_{c t}=R_{c t 1}+R_{c t 2}$. This was derived from the low frequency impedance by 
subtracting the high frequency intercept on the real axis due to series resistance, $\mathrm{R}_{\mathrm{s}}$, and the lower frequency contribution of the Warburg diffusion element. $R_{c t}$ is, thus, the charge-transfer resistance of the electrochemical reactions at the photo-anode and the counter electrode. Notice that the photoanode is the same in all the cells, thus the variation of $\mathrm{R}_{\mathrm{ct}}$ reflects the contribution of the counter electrode. The high frequency intercept measured under open circuit condition is related to the series resistance $\left(\mathrm{R}_{\mathrm{s}}\right)$. It accounts for the resistance of the conductive materials in the cell with contributions from the FTO substrate layer, porous electrode material, current collector and resistivity of the electrolyte. $R_{s}$ and $R_{c t}$ values are summarized in Table 3. Unexpectedly, the CNF prepared at low temperature (CNF550), characterized by the lowest graphitization degree, showed the lowest $\mathrm{R}_{\mathrm{s}}$. This could be due to a different compactness of the nanopowder, which is highly influenced by the CNF diameter. Low temperature preparation route produces thin filaments (see Table 1) leading to an electrode with a higher density than using thicker filaments. Fig. 8 shows the bulk resistivity of the powders as a function of the solid volume fraction. From this analysis, it appears that high compaction produces lower resistivity, thus the best electrochemical behavior of the CNF550, and in particular the lowest $\mathrm{R}_{\mathrm{s}}$, should be attributed to an enhanced arrangement of the filaments within the electrode. For what concerns the CNF prepared at the highest temperature, the bulk resistivity decreases significantly with the increase of density (Fig. 8); yet, it is characterized by the largest average diameter (63 nm, see Table 1), which influences negatively the compaction degree. However, it is pointed out that this sample shows the highest intrinsic conductivity (see Fig. 4), due to its high graphitization degree, which determines the slightly lower $R_{\mathrm{s}}$ value compared to CNF650. Regarding the charge transfer resistance, $\mathrm{R}_{\mathrm{ct}}$, it appears that this process is controlled by the graphitization degree rather than porosity. Notice that in this one-dimensional type of carbon materials, porosity is the result of the interstitial space among filaments, leading to wide pores in the range of meso-macropores, as previously discussed. This essentially means that no significant diffusion constraints are found in CNF-based counter electrodes and the electron transfer process is 
controlled by the surface graphitization. The graphitization degree is favored at high temperature preparation, as revealed from Raman spectroscopy and X-ray diffraction patterns (see Table 1), consequently lower values of $R_{c t}$ are observed for the CNF prepared at high temperature in comparison with the defect-rich CNF550. Nonetheless, it seems that there is a correlation between $\mathrm{R}_{\mathrm{s}}$ values, which represents the ohmic contribution, and conversion efficiencies of the cells. In contrast to carbon blacks [41], the series resistance appears as a critical parameter to consider when preparing counter electrodes based on highly graphitic carbon nanofibers, which in turn is significantly influenced by the compaction of the nanofilaments.

To further investigate the effect of CE thickness, three cells were prepared varying in carbon loading. These are characterized by a thickness of $10 \mu \mathrm{m}, 30 \mu \mathrm{m}$ and $50 \mu \mathrm{m}$, using in all cases the best CNF (CNF550). The photocurrent-voltage curves are shown in Fig. 9 and the resulting parameters are summarized in Table 4. Notice that increasing electrode thickness from $10 \mu \mathrm{m}$ to 50 $\mu \mathrm{m}$ leads to better performance in terms of open circuit voltage, short-circuit current density, fill factor and efficiency. Wang et al. obtained similar behavior in the application of mesoporous carbon to counter electrode for DSSCs [41]. They attributed it to the presence of a minimum charge transfer resistance, this is, they obtained a volcano-shaped dependence of reaction kinetics with carbon loading. Indeed, as shown in the Nyquist plots of Fig. 10 and summarized in Table 5, a minimum $R_{c t}$ was obtained for the $30 \mu \mathrm{m}$ thickness CE based on CNF550. Yet, the higher series resistance of the $30 \mu \mathrm{m}$ thick CE compared with the thickest CE results in lower performance. This analysis confirms the importance of low $\mathrm{R}_{\mathrm{s}}$ for the CNF-based counter electrodes. It must be pointed out that further optimization of the cell in terms of electrolyte thickness and photoanode manufacturing may enhance the conversion efficiency but substantially increase the overall cost.

A short time-study was carried out in half-cell configuration using a conventional threeelectrode set-up, without stirring. This set-up allows to evaluate the CNF550 behaviour during the 
1 reduction process at a well defined overpotential. Current vs. time curves were registered at $-0.4 \mathrm{~V}$

2 vs. the reversible potential for the redox couple $\mathrm{I}^{-} / \mathrm{I}_{3}{ }^{-}$.

3 This operating condition corresponds to the iodine reduction at a rate close to that recorded in the

4 DSSC under $\mathrm{I}_{\mathrm{sc}}$ conditions. In Fig. 11, the current density for $\mathrm{I}_{3}{ }^{-}$reduction at the carbon nanofibers-

5 electrolyte interface shows a progressive decrease with time. However, the initial current is almost

6 re-gained after storing the cell for about $16 \mathrm{~h}$ without operation. Thus, the observed reversible loss

7 may be attributed to the accumulation of $\mathrm{I}^{-}$species on the carbon nanofiber surface causing a 8 blocking effect of the catalytic sites. The restoration of initial conditions requires time because of

9 the relevant diffusion length of the iodine/iodide species in the hal-cell. This aspect may be 10 conveniently addressed in the DSSC by using a thin electrolyte layer between the two electrodes. 


\section{Conclusions}

Four different highly graphitic carbon nanofibers have been in-house synthesized and studied as counter electrode in dye-sensitized solar cells. Physico-chemical characterization of CNF has been carried out by TEM, XRD, BET and conductivity analyses. Electrochemical investigation on DSSCs has been performed by current-voltage polarization and electrochemical impedance spectroscopy.

The carbon nanofibers, prepared at increasing temperatures, show increasing diameters, increasing graphitization and decreasing surface area. The best cell performance is given by the counter electrode based on the carbon nanofiber synthesized at the lowest temperature. This $\mathrm{CNF}$ presents the smallest average diameter $(24 \mathrm{~nm})$, the highest surface area $\left(183 \mathrm{~m}^{2} \mathrm{~g}^{-1}\right)$ and the highest porosity $\left(0.53 \mathrm{~cm}^{3} \mathrm{~g}^{-1}\right)$. Even if the apparent electrical conductivity increases with the graphitization degree, a high compactness degree of thin nanofilaments results in low series resistance for the system, explaining the significant enhancement of performance for low temperature prepared carbon nanofibers. The cross-analysis of performance, electrode characteristics and CNF features evidences the key role played by the high graphitization degree of this kind of material, whose electrochemical activity is mainly controlled by the surface area and surface graphitization. Compared to literature under similar conditions and taking into consideration low cost manufacturing of DSSC components, CNFs represent a good alternative to Pt-based counter electrodes.

\section{Acknowledgements}

CNR-ITAE authors acknowledge the financial support of the POR Project ñFotovoltaico di III generazione: sviluppo di celle solari senzibilizzate con coloranti estratti da prodotti vegetali siciliani (SAGRO)ò. Authors also thank the financial support of the bilateral CNR (Italy) ï CSIC (Spain) joint agreement 2011-2012 (project Baglio/Lazaro 2010IT0026). 


\section{References}

[1] M. Grätzel, J. Photochem. Photobiol. A Chem. 164 (2004) 3-14.

[2] V. Ganapathy, B. Karunagaran, S.W. Rhee, J. Power Sources 195 (2010) 5138-5143.

[3] W. Kwon, S.W. Rhee, J. Power Sources 196 (2011) 10532-10537.

[4] S. Zhang, X. Yang, Y. Numata, L. Han, Energy Environ. Sci. 6 (2013) 1443-1464.

[5] P. Calandra, G. Calogero, A. Sinopoli, P.G. Gucciardi, Int. J. Photoenergy, Article ID 109495 (2010) 1-15.

[6] G. Calogero, F. Bonaccorso, O.M. Maragò, P.G. Gucciardi, G. Di Marco, Dalton Trans. 39 (2010) 2903-2909.

[7] T. Murakami, M. Grätzel, Inorganica Chimica Acta 361 (2008) 572-580.

[8] B.K. Koo, D.Y. Lee, H.J. Kim, J.S. Song, H.J. Kim, J. Electroceram. 17 (2006) 79-82.

[9] X. Fang, T. Ma, G. Guan, M. Akiyama, T. Kida, E. Abe, J. Electroanal. Chem. 570 (2004) 257263.

[10] R. Kern, R. Sastrawan, J. Ferber, R. Stangl, J. Luther, Electrochim. Acta 47 (2002) 4213-4225.

[11] S. Sakaguchi, H. Ueki, T. Kato, T. Kado, R. Shiratuchi, W. Takashima, K. Kaneto, S. Hayase, J. Photochem. Photobiol. A 164 (2004) 117-122.

[12] S. Murai, S. Mikoshiba, H. Sumino, S. Hayase, J. Photochem. Photobiol. A 148 (2002) 33-39.

[13] A. Kay, M. Grätzel, Sol. En. Mat. Sol. C. 44 (1996) 99-117.

[14] E. Ramasamy, W.Y. Lee, J.S. Song, Appl. Phys. Lett. 90 (2007) 173103.

[15] A. Murakamy, T.N.S. Ito, Q. Wang, M.K. Nazeeruddin, T. Bessho, I. Cesar, P. Liska, R.H. Baker, P. Comte, P. Pechy, M. Grätzel, J. Electrochem. Soc. 153 (2007) A2255.

[16] T. Hino, Y. Ogawa, N. Kuramoto, Carbon 44 (2006) 880-887.

[17] Z. Huang, X. Liu, K. Li, Y. Luo, H. Li, W. Song, L. Chen, Q. Meng, Electrochem. Commun. 9 (2007) 596-598. 
1 [18] K. Imoto, K. Takahashi, T. Yamaguchi, T. Komura, J. Nakamura, K. Murata, Sol. Energ. Mat. Sol. Cells 79 (2003) 459-469.

[19] Z. Huang, Z. Liu, K. Li, D. Li, Y. Luo, H. Li, W. Song, L. Chen, Q. Meng, Electrochem. Commun. 9 (2007) 596-598.

[20] W.I. Lee, E. Ramasamy, D.Y. Lee, J.S. Song, J. Photochem. Photobiol. A Chem. 194 (2008) 27.

[21] W.I. Lee, E. Ramasamy, D.Y. Lee, J.S. Song, Sol. Energ. Mat. Sol. Cells 92 (2008) 814.

[22] A. Hauch, A. Georg, Electrochim. Acta 46 (2001) 3457-3466.

[23] W. Kwon, J.M. Kim, S.W. Rhee, J. Mater. Chem. A 1 (2013) 3202-3215.

[24] P. Joshi, L. Zhang, Q. Chen, D. Galipeau, H. Fong, Q. Qiao, ACS Applied Materials \& Interfaces 2 (2010) 3572-3577.

[25] G. Veerappan, W. Kwon, S.W. Rhee, J. Power Sources 196 (2011) 10798-10805.

[26] P. Joshi, Z. Zhou, P. Poudel, A. Thapa, X.F. Wu, Q. Qiao, Nanoscale 4 (2012) 5659-5664.

[27] A. Yousef, M.S. Akhtar, N.A.M. Barakat, M. Motlak, O.B. Yang, H.Y. Kim, Electrochim. Acta 102 (2013) 142-148.

[28] N.A.M. Barakat, M.S. Akhtar, A. Yousef, M. El-Newehy, H.Y. Kim, Chem. Eng. J. 211-212 (2012) 9-15.

[29] P. Poudel, L. Zhang, P. Joshi, S. Venkatesan, H. Fong, Q. Qiao, Nanoscale 4 (2012) 47264730.

[30] http://pyrografproducts.com

[31] http://www.cheaptubesinc.com

[32] http://www.platinum.matthey.com

[33] V. Baglio, M. Girolamo, V. Antonucci, A.S. Aricò, Int. J. Electrochem. Sci. 6 (2011) 33753384. 
1 [34] S. Ito, P. Chen, P. Comte, M.K. Nazeeruddin, P. Liska, P. Pechy, M. Grätzel, Prog. Photovolt: Res. Appl. 15 (2007) 603.

[35] S. Hore, P. Nitz, C. Vetter, C. Prahl, M. Niggemann, R. Kern, Chem. Commun. 15 (2005) 2011.

[36] S. Hore, C. Vetter, R. Kern, H. Smit, A. Hinsch, Sol. Energ. Mat. Sol. Cells 90 (2006) 1176.

[37] Z.S. Wang, H. Kawauchi, T. Kashima, H. Arakawa, Coordinat. Chem. Rev. 248 (2004) 1381.

[38] J.-K. Lee, B.-H. Jeong, S.-I. Jang, Y.-S. Yeo, S.-H. Park, J.-U. Kim, Y.-G. Kim, Y.-W. Jang, M.-R. Kim, J. Mater. Sci.: Mater. Electron. 20 (2009) S446.

[39] D. Sebastián, I. Suelves, R. Moliner, M.J. Lázaro, Carbon 48 (2010) 4421-4431.

[40] M.J. Lázaro, D. Sebastián, I. Suelves, R. Moliner, J. Nanosci. Nanotechnol. 9 (2009) 43534359.

[41] T. Denaro, V. Baglio, M. Girolamo, V. Antonucci, A.S. Aricò, F. Matteucci, R. Ornelas, J. Appl. Electrochem. 39 (2009) 2173-2179.

[42] Q. Wang, J. Moser, M. Grätzel, J. Phys. Chem. B 109 (2005) 14945.

[43] J. Van de Lagemaat, N.G. Park, A.J. Frank, J. Phys. Chem. B 104 (2000) 2044.

[44] G. Wang, W. Xing, S. Zhuo, J. Power Sources 194 (2009) 568-573. 
Table 1. Structural features of CNFs derived from XRD, Raman, TEM and physisorption analyses.

\begin{tabular}{lcccccc}
\hline Sample & $\begin{array}{c}\text { Interlayer } \\
\text { distance } \\
(\mathrm{nm})^{a}\end{array}$ & $\begin{array}{c}\text { Crystal size } \\
c \text {-axis } \\
(\mathrm{nm})^{a}\end{array}$ & $\begin{array}{c}\text { Raman } \\
\mathrm{I}_{\mathrm{D}}: \mathrm{I}_{\mathrm{G}}\end{array}$ & $\begin{array}{c}\text { Filament } \\
\text { diameter }\end{array}$ & $\begin{array}{c}\mathrm{S}_{\mathrm{BET}} \\
\left(\mathrm{m}^{2} \mathrm{~g}^{-1}\right)^{b}\end{array}$ & $\begin{array}{c}3_{\text {pore }} \\
\left(\mathrm{cm}^{3} \mathrm{~g}^{-1}\right)\end{array}$ \\
\hline CNF550 & 0.337 & 6.0 & $2.4: 1$ & $24 \pm 11$ & 183 & 0.53 \\
CNF600 & 0.336 & 6.9 & $1.9: 1$ & $28 \pm 13$ & 150 & 0.43 \\
CNF650 & 0.336 & 8.7 & $1.5: 1$ & $46 \pm 22$ & 113 & 0.32 \\
CNF750 & 0.337 & 9.6 & $1: 1$ & $63 \pm 17$ & 92 & 0.24 \\
\hline
\end{tabular}

${ }^{b} \mathrm{BET}$ equation applied to $\mathrm{N}_{2}$ physisorption isotherms.

4

Table 2. Performance characteristics of DSSCs with different counter electrodes.

\begin{tabular}{lcccc}
\hline Counter & $\mathrm{V}_{\mathrm{oc}}$ & $\begin{array}{c}\mathrm{j}_{\mathrm{sc}} \\
\left(\mathrm{mA} \mathrm{cm}^{-2}\right)\end{array}$ & $\mathrm{FF}$ & $\eta$ \\
electrode & $(\mathrm{V})$ & 7.4 & 0.42 & $(\%)$ \\
\hline CNF550 & 0.71 & 5.3 & 0.53 & 1.86 \\
CNF600 & 0.67 & 5.6 & 0.47 & 1.80 \\
CNF650 & 0.69 & 5.2 & 0.50 & 1.75 \\
CNF750 & 0.68 & & & \\
\hline
\end{tabular}

6

Table 3. Resistance values of DSSCs with different counter electrodes.

\begin{tabular}{lcc}
\hline $\begin{array}{l}\text { Counter } \\
\text { electrode }\end{array}$ & $\begin{array}{c}\mathrm{R}_{\mathrm{s}} \\
(\mathrm{q} \mathrm{cm})\end{array}$ & $\begin{array}{c}\mathrm{R}_{\mathrm{ct}} \\
(\mathrm{q} \mathrm{cm})\end{array}$ \\
\hline CNF550 & 8.5 & 30 \\
CNF600 & 9.7 & 12 \\
CNF650 & 13.7 & 10 \\
CNF750 & 11.7 & 18 \\
\hline
\end{tabular}


Table 4. Effect of CE thickness on performance characteristics of DSSCs using CNF550.

\begin{tabular}{ccccc}
\hline $\begin{array}{c}\text { Thickness } \\
(\mu \mathrm{m})\end{array}$ & $\mathrm{V}_{\mathrm{oc}}$ & $\mathrm{j}_{\mathrm{sc}}$ & $\mathrm{FF}$ & $\eta$ \\
& $(\mathrm{V})$ & $\left(\mathrm{mA} \mathrm{cm}^{-2}\right)$ & & $(\%)$ \\
\hline 10 & 0.64 & 6.0 & 0.36 & 1.40 \\
30 & 0.66 & 6.4 & 0.40 & 1.64 \\
50 & 0.71 & 7.4 & 0.42 & 2.17 \\
\hline
\end{tabular}

4

Table 5. Effect of CE thickness on resistance values of DSSCs using CNF550.

\begin{tabular}{ccc}
\hline $\begin{array}{c}\text { Thickness } \\
(\mu \mathrm{m})\end{array}$ & $\begin{array}{c}\mathrm{R}_{\mathrm{s}} \\
\left(\mathrm{q} \mathrm{cm}^{2}\right)\end{array}$ & $\begin{array}{c}\mathrm{R}_{\mathrm{ct}} \\
\left(\mathrm{q} \mathrm{cm} \mathrm{cm}^{2}\right)\end{array}$ \\
\hline 10 & 12.2 & 80 \\
30 & 10.1 & 16 \\
50 & 8.5 & 30 \\
\hline
\end{tabular}

8 


\section{Captions to figures}

2 Figure 1. XRD patterns of pristine carbon nanofibers.

Figure 2. Representative HRTEM images of CNFs: (a) CNF550; (b) CNF600; (c) CNF650; (d) CNF750.

5 Figure 3. Nitrogen adsorption-desorption isotherms at $-196^{\circ} \mathrm{C}$.

6 Figure 4. Electrical conductivity of CNFs, effect of pressure on the powder.

Figure 5. Polarization curves using CNFs as counter electrode.

Figure 6. Influence of CNF surface area and crystallinity on (a) efficiency and fill factor; (b) shortcircuit current density and open circuit voltage.

Figure 7. Impedance spectra using CNFs as counter electrode at OCV.

Figure 8. Bulk resistivity of CNFs as a function of solid volumetric fraction.

Figure 9. Effect of CE thickness on polarization curves for CNF550.

Figure 10. Effect of CE thickness on impedance spectra for CNF550 at OCV. 


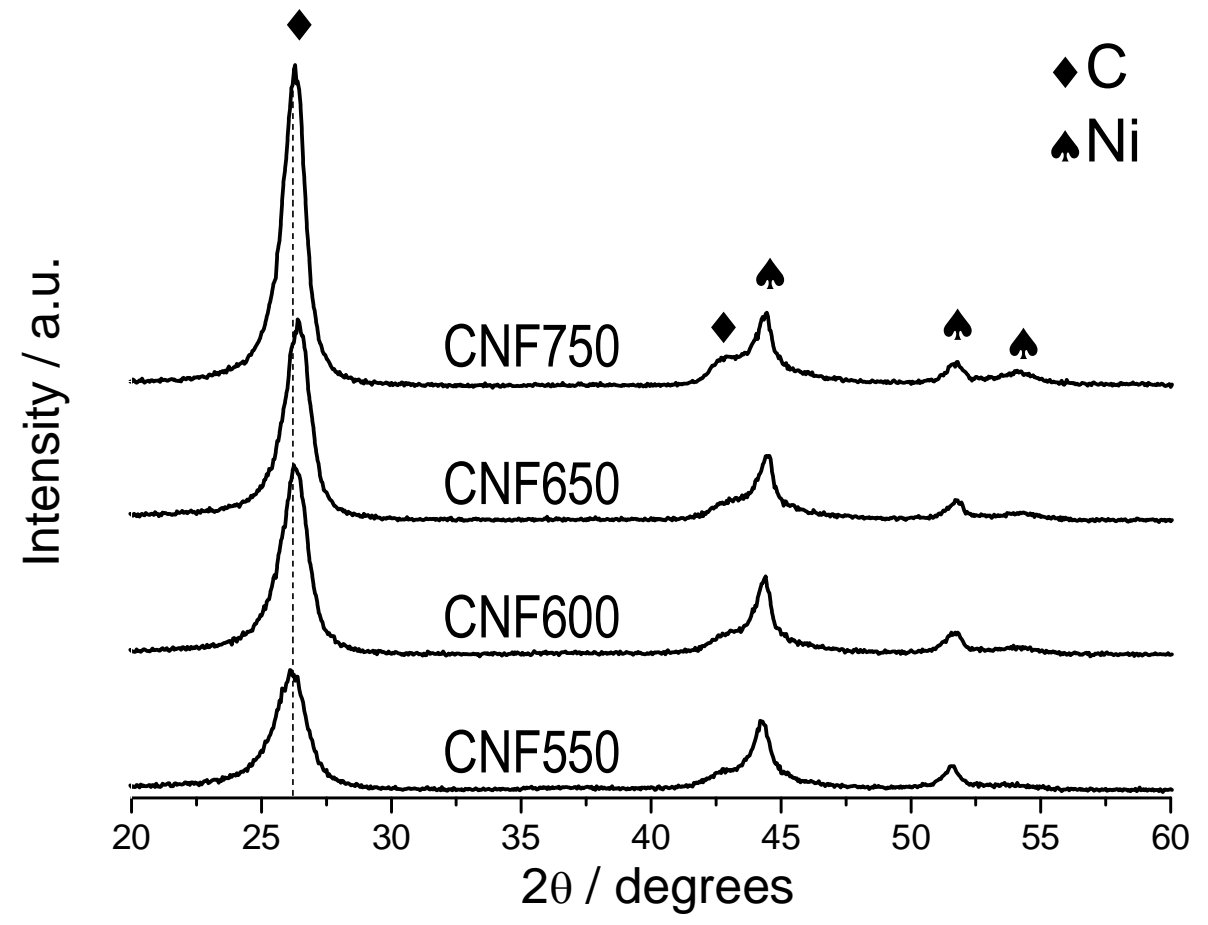

Figure 1 

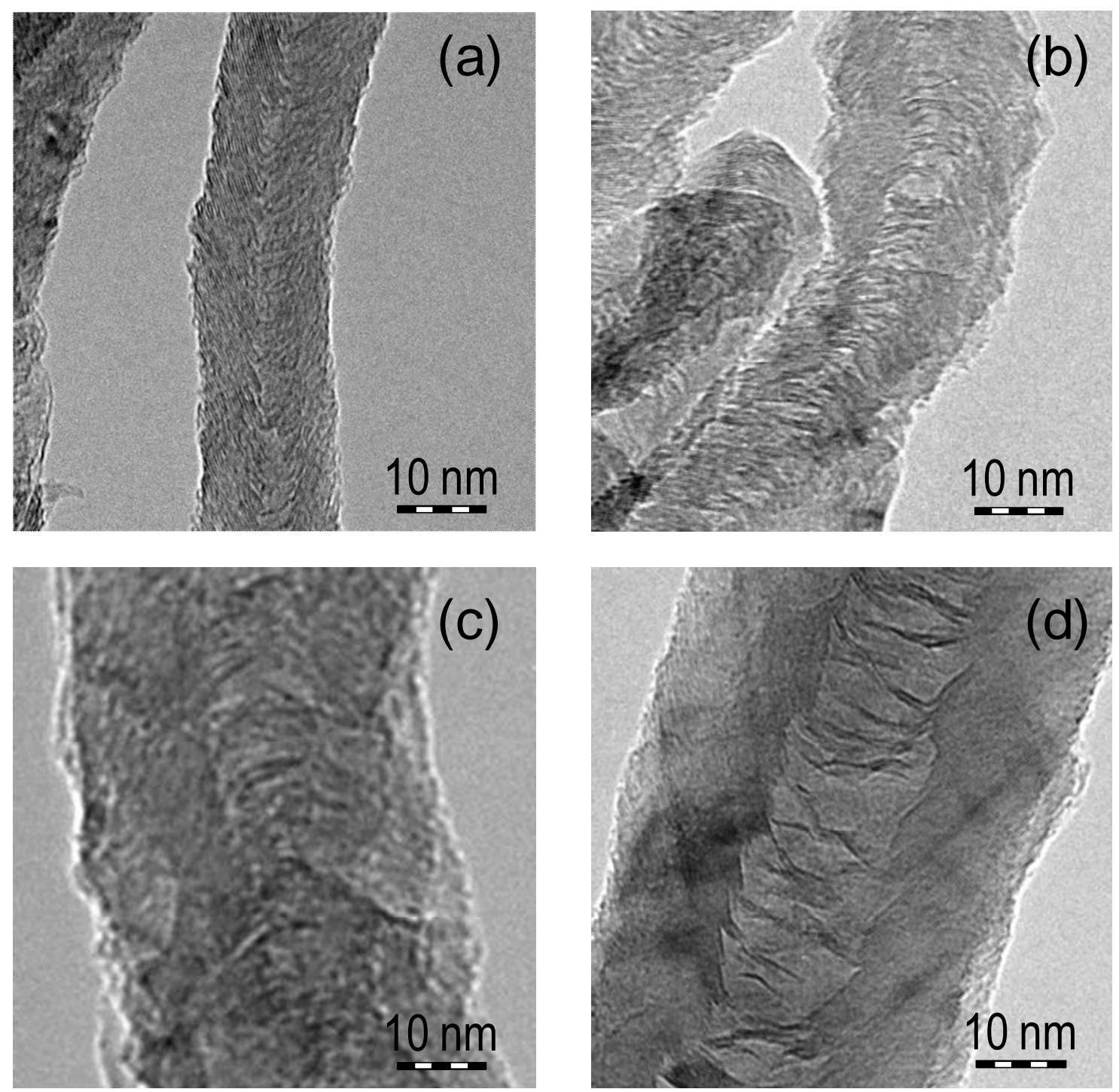

4

$5 \quad$ Figure 2

6

7

8

9 

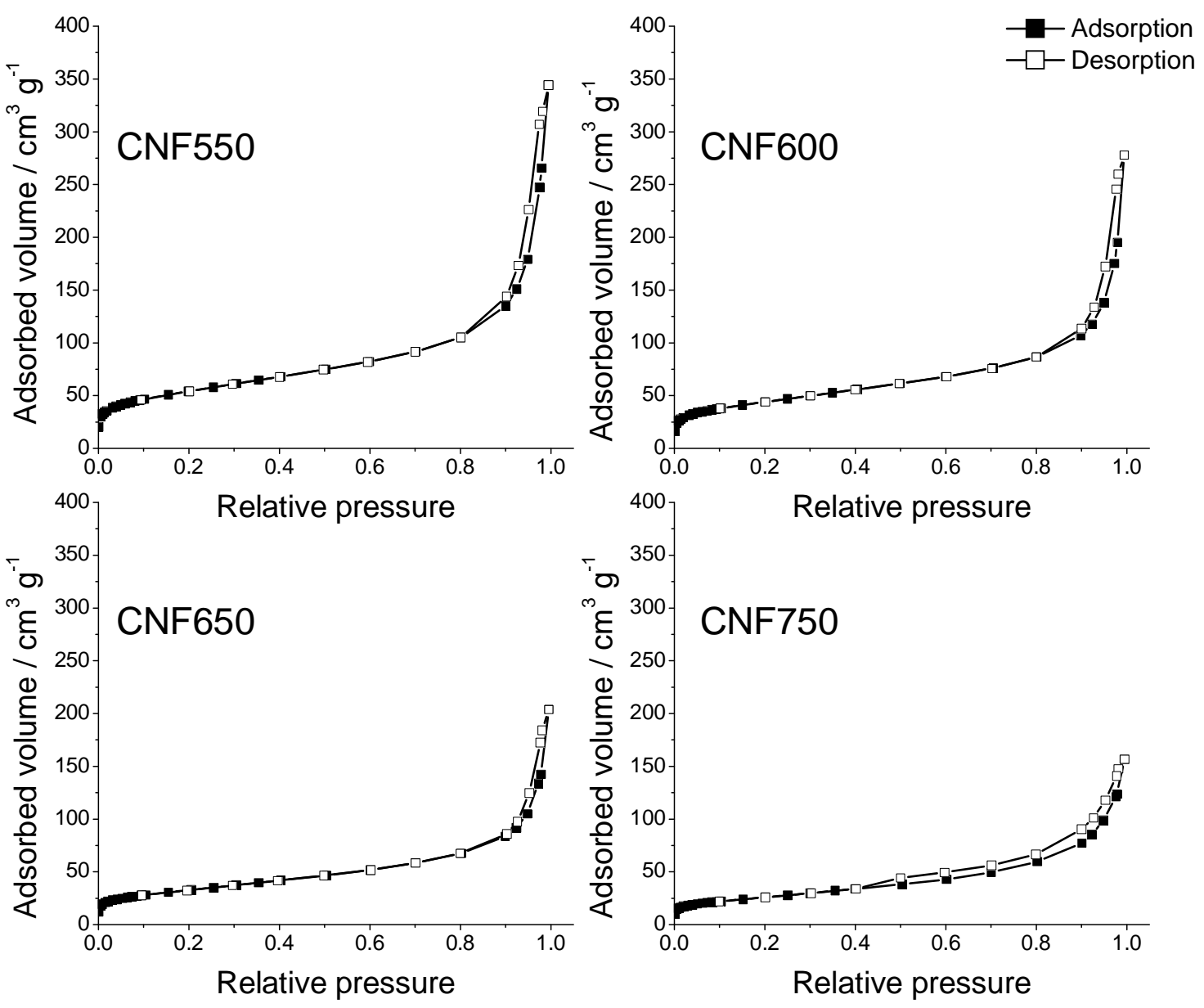

Figure 3 


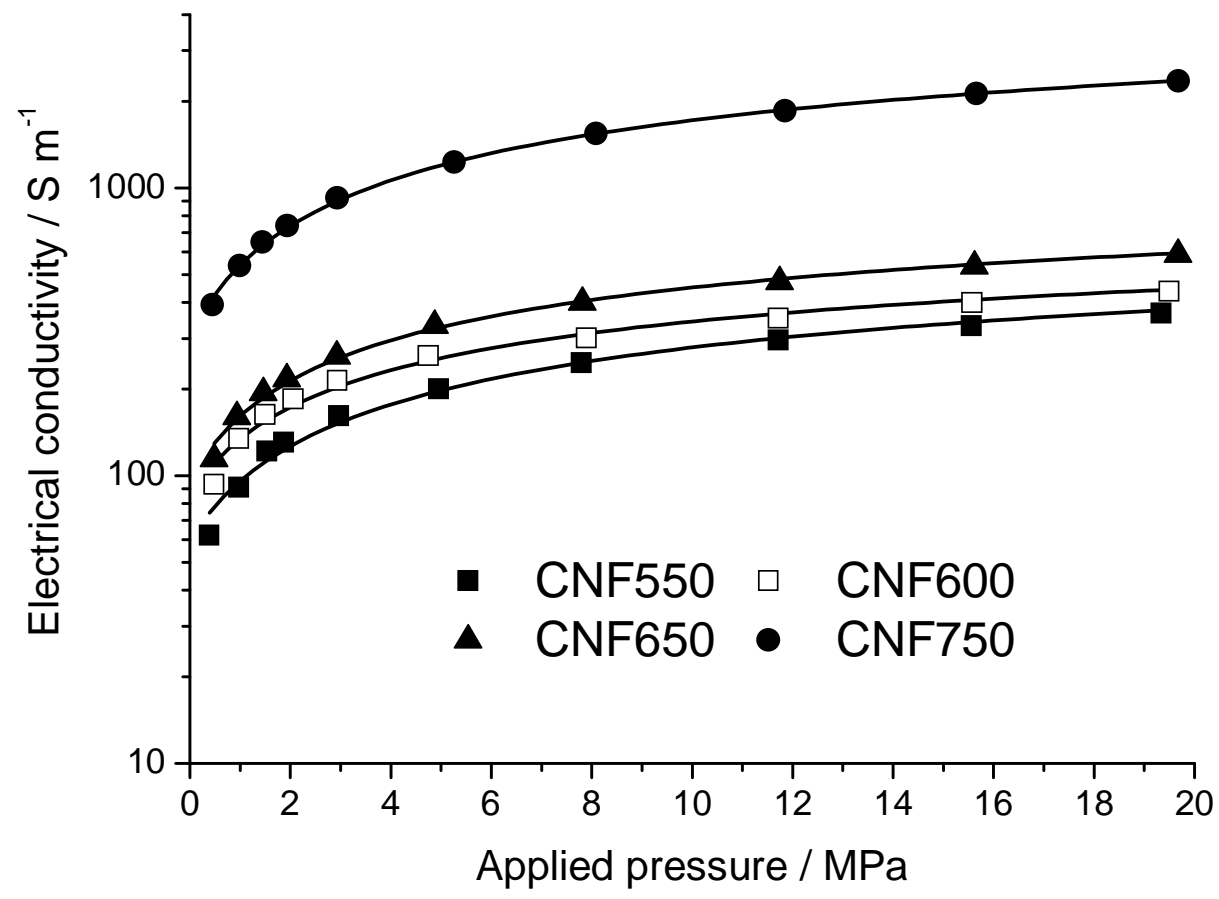

Figure 4

6

7

8

9 


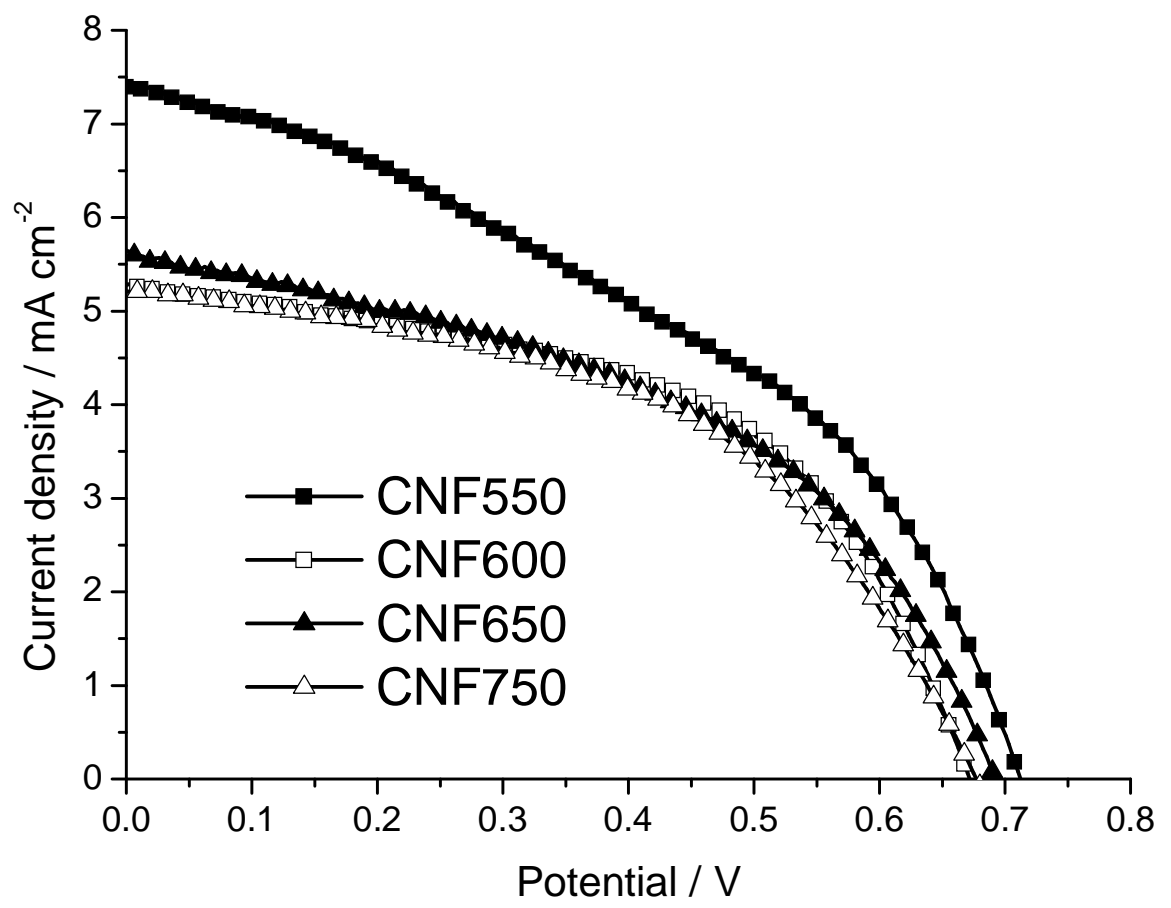

Figure 5

6

7 

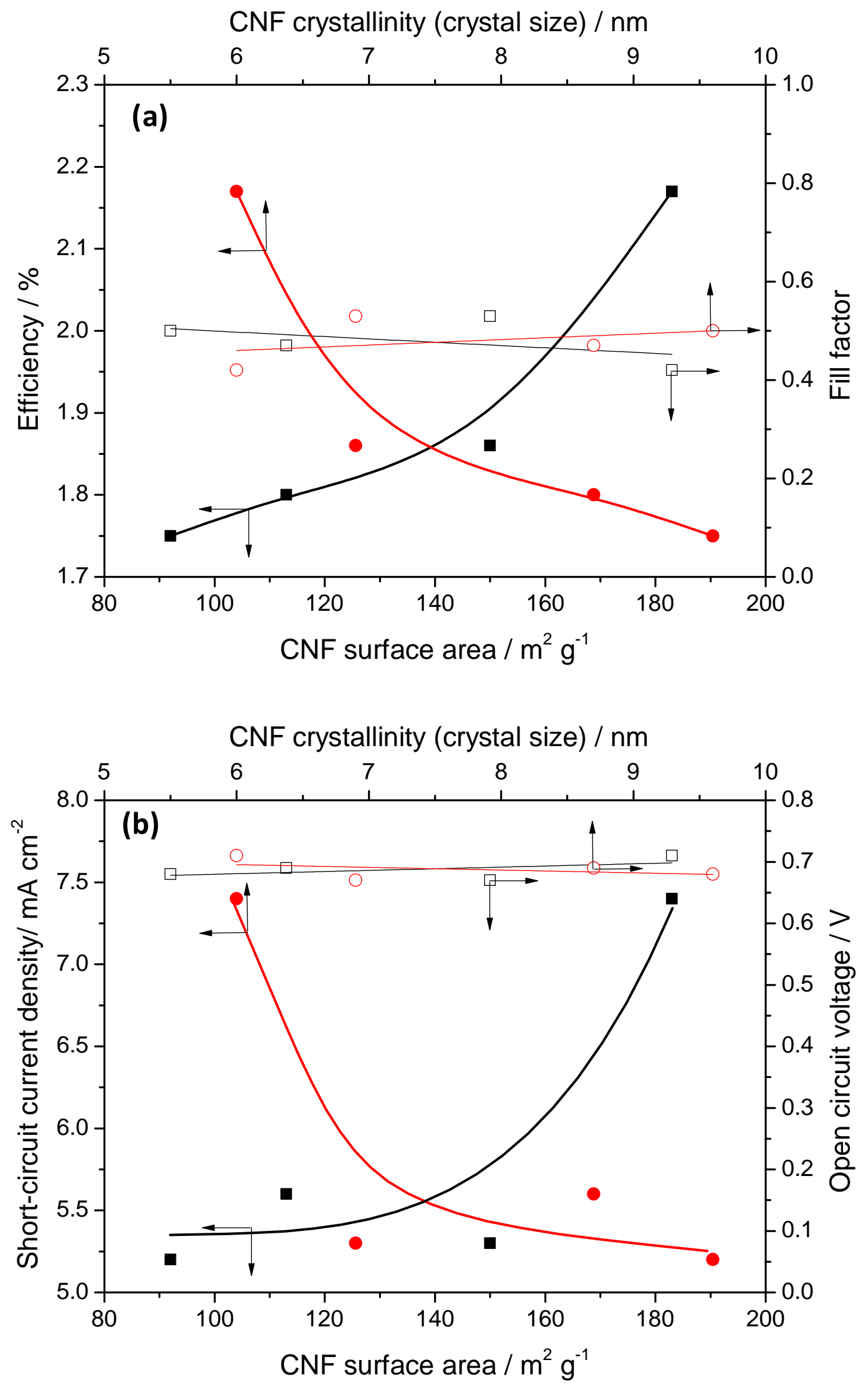

2 Figure 6 
9

$$
\begin{aligned}
& --- \text { CNF550 } \\
& -\square-\text { CNF600 } \\
& -\triangle-\text { CNF650 } \\
& -\triangle-\text { CNF750 }
\end{aligned}
$$

ह 30

ह $25-$

N

15 10

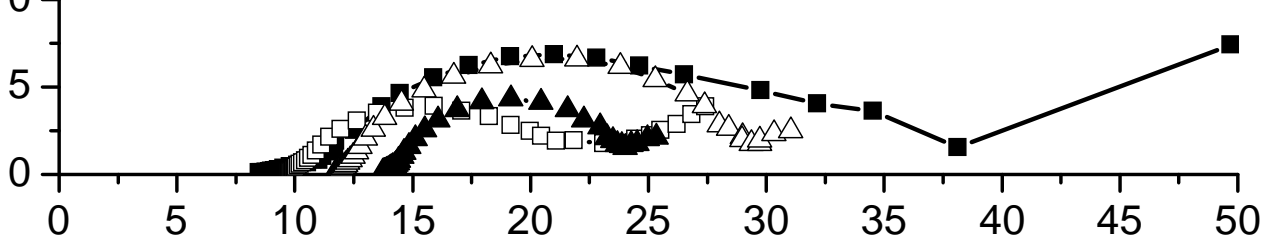

Z' / ohm cm²

\section{Figure 7}




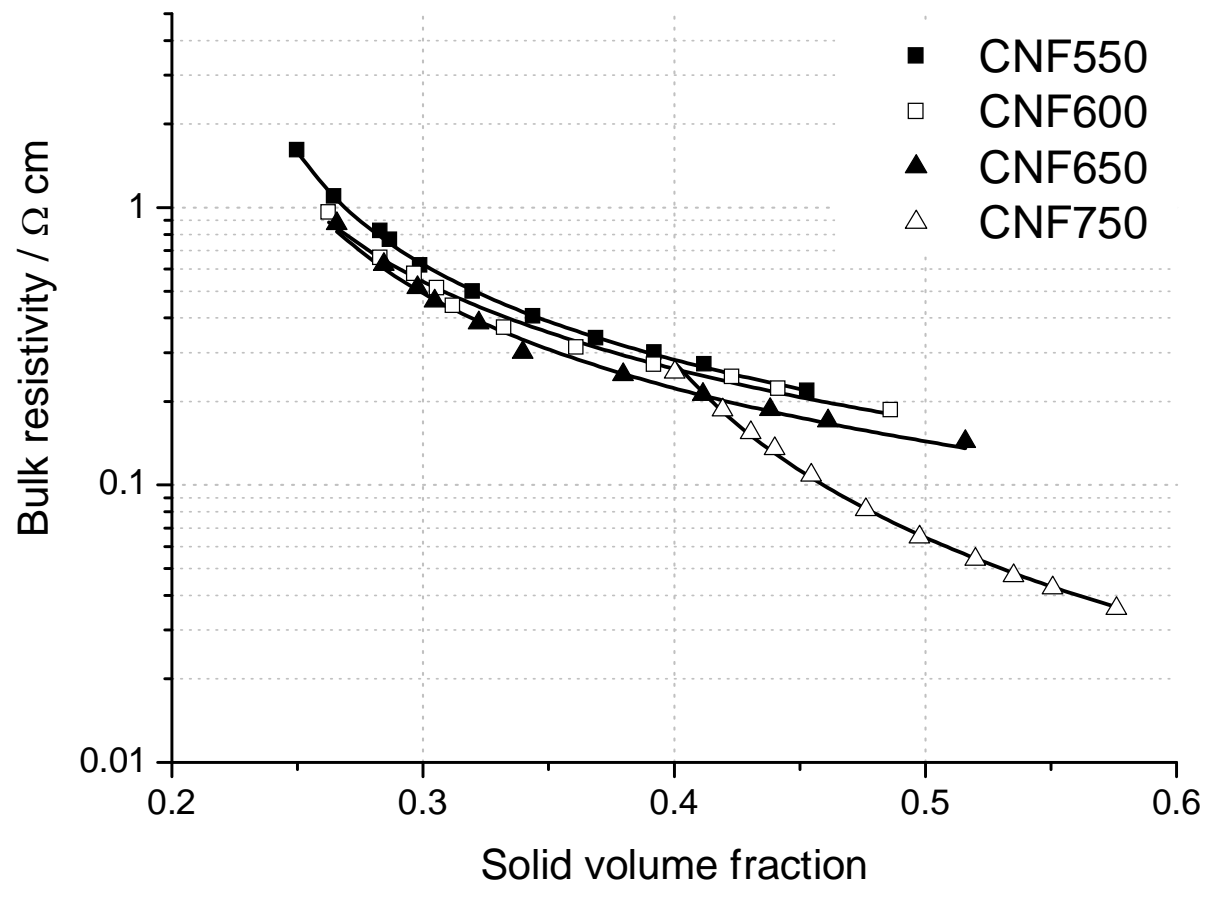

Figure 8

6

7

8

9 


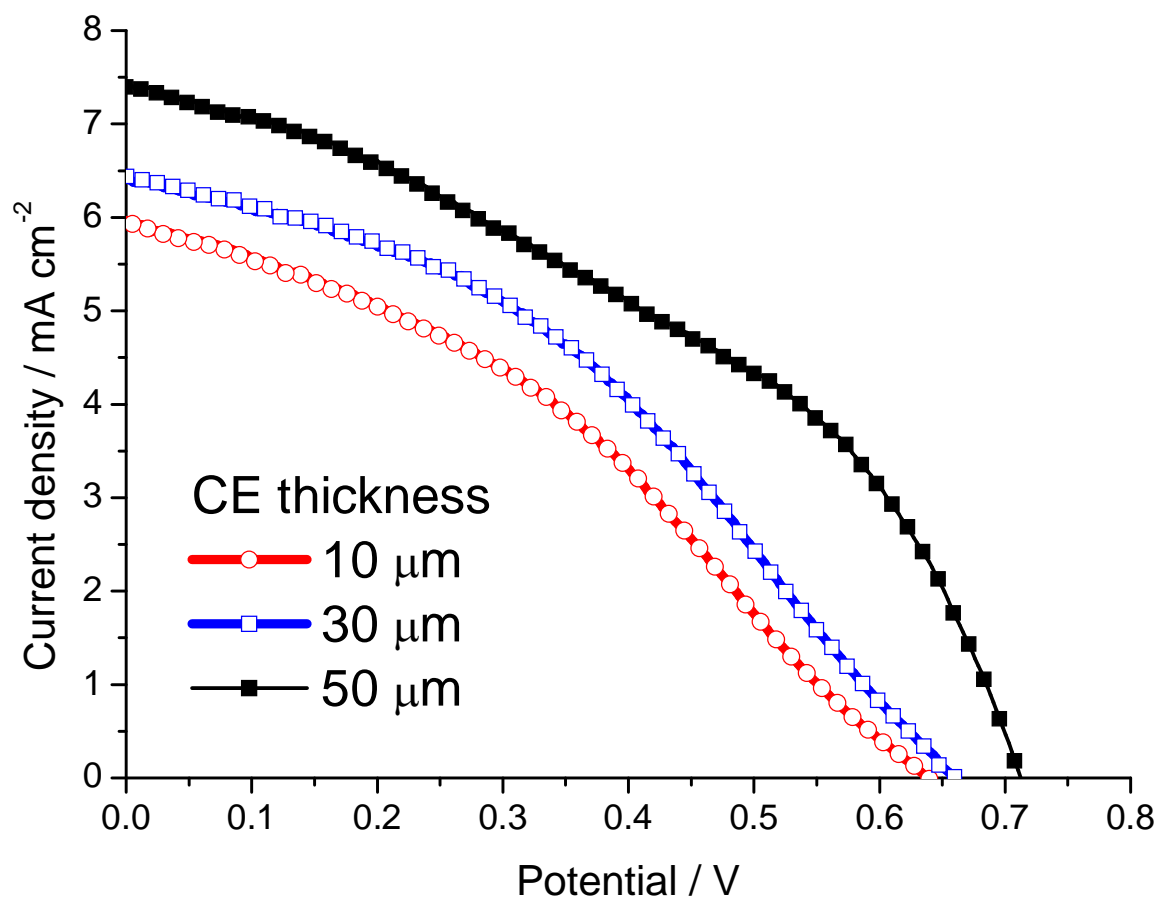

Figure 9 


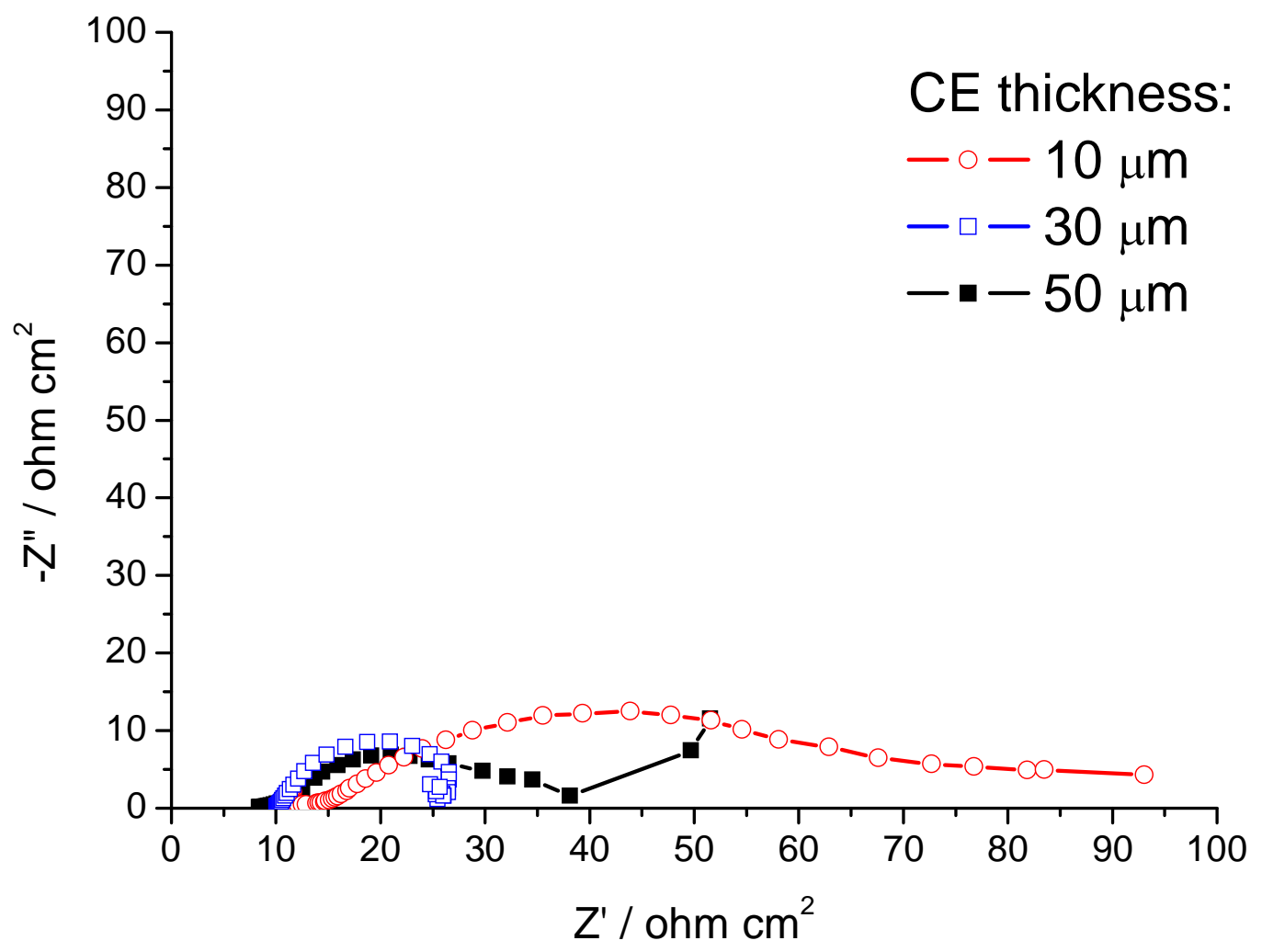




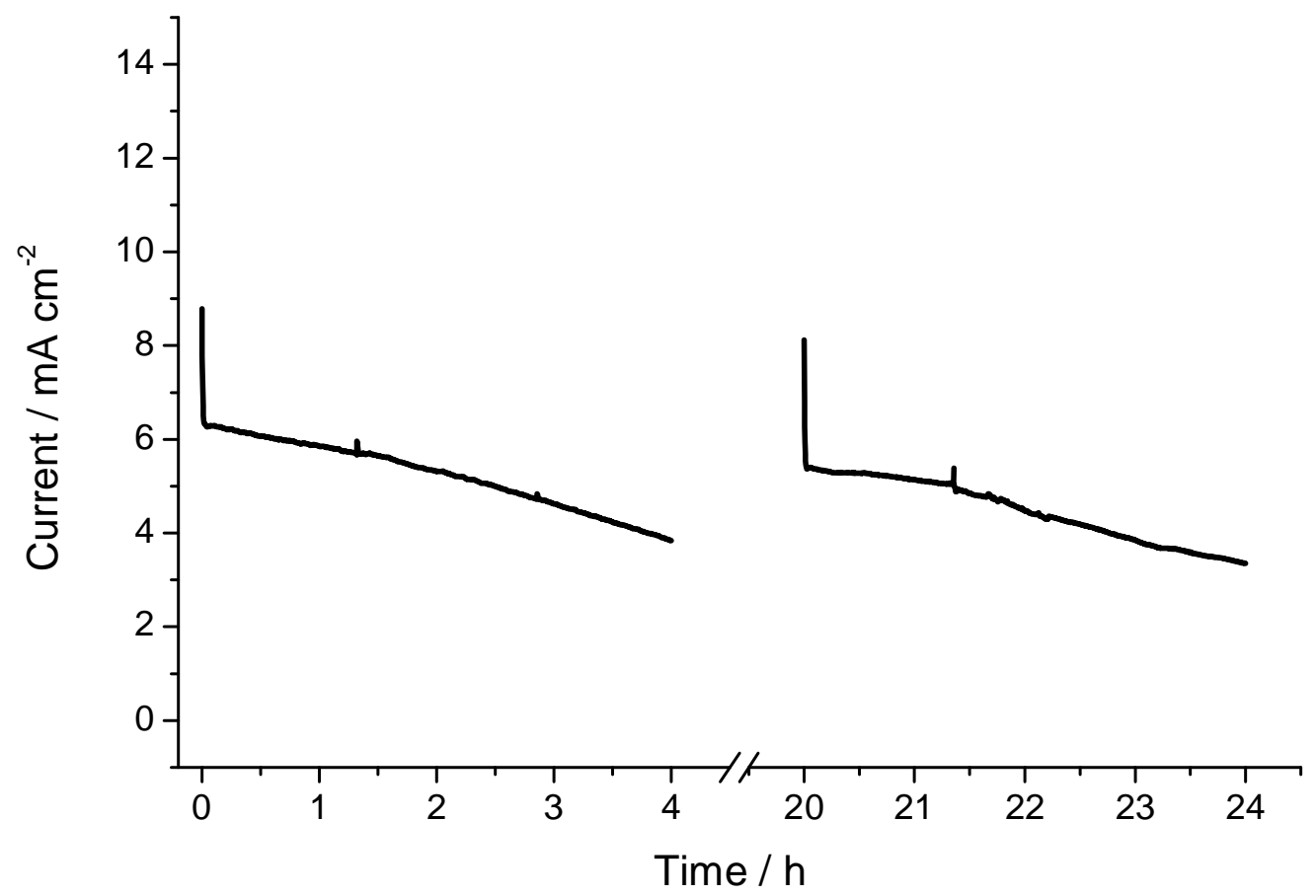

$6 \quad$ Figure 11

7

8

9

10 